\title{
Human Trafficking-Related Corruption as a Security Challenge: A Study of Cases in South-Eastern Europe
}

\author{
Silvia Rodríguez-López, PhD student \\ University of A Coruna (Spain) \\ s.rodriguezl@udc.es
}

\begin{abstract}
Although corruption is often mentioned as a key factor in human trafficking, so far only a few studies have challenged the lack of data available in this field to dig into the relationship between these interrelated crimes. This paper carries out an analysis of real cases of trafficking-related corruption in Europe, which had been reported in academic sources as well as various institutional documents, in order to offer an overview of the various patterns of this phenomenon. This analysis shows that corruption can reach public officials in different positions, be used in every stage of the trafficking process, and in every kind of exploitation. Subsequently, the paper briefly examines the main legislative and institutional measures for combatting this specific form of criminality at the international and European level. It is important to highlight the role of the Programme against Corruption and Organised Crime in South-eastern Europe (PACO), created by the Council of Europe, which pioneered the elaboration of proposals to address this specific problem. Overall, both the analysis of the patterns of public officials' involvement in human trafficking as well as the response to this crime serve as a basis to consider the convenience of approaching trafficking-related corruption as a challenge to security.
\end{abstract}

Keywords: human trafficking; corruption; national security; human security 


\section{Securuarity}

\section{INTRODUCTION}

Although the first measures against human trafficking date back to the $19^{\text {th }}$ century and the fight against the so-called "white slavery traffic", it was not until recent years that an internationally accepted definition of this crime was reached. The Protocol to Prevent, Suppress and Punish Trafficking in Persons, Especially Women and Children, supplementing the United Nations Convention against Transnational Organized Crime, adopted on 15 November $2000^{245}$, defines human trafficking as a process that requires three elements: act, means and purpose. The act can be the recruitment, transportation, transfer, harbouring or receipt of persons. The means are threats, the use of force or other forms of coercion, abduction, fraud, deception, abuse of power or of a position of vulnerability, or giving or receiving payments or benefits to achieve the consent of one person having control over another. The purpose is the exploitation of the person, including, at least, sexual exploitation, forced labour or services, slavery or practices similar to slavery, servitude or the removal of organs. ${ }^{246}$ Since the adoption of the Palermo Protocol, many countries have modified their national legislations to implement this and other supranational anti-trafficking instruments. Human trafficking has also become a matter of growing importance in academic literature. However, the challenge of putting an end to what has been described as "modern slavery" still remains (or perhaps is even growing).

When trying to identify the key factors that contribute to the existence of human trafficking, governmental corruption is often mentioned as a relevant predictor, together with other macro-level conditions such as poverty and the lack of economic opportunities (Bales, 2005; Zhang \& Pineda, 2008). So far only a few studies have challenged the lack of data available in this field to dig into the relationship between these interrelated crimes. Most of them have tried to confirm the hypothesis that corruption impedes the correct implementation of anti-trafficking strategies and

\footnotetext{
245 Hereinafter referred to as "Palermo Protocol" and "UNTOC" respectively.

${ }^{246}$ It is necessary to clarify that, although the definition of human trafficking provided by the Palermo Protocol has served as the basis for European and national anti-trafficking instruments, this initial concept has been expanded. For instance, Directive 2011/36/EU on preventing and combating trafficking in human beings and protecting its victims adds the exchange or transfer of control over persons among the actions of human trafficking; and the exploitation of criminal activities and begging to the types of exploitation foreseen in the Palermo Protocol.
} 


\section{Seccurity}

facilitates trafficking by finding correlations between levels of perceived corruption and the extent to which a country makes efforts to combat trafficking (Liday, 2001; Van Dijk \& Van Mierlo, 2011; Cho, Dreher \& Neumayer, 2014). These analyses tried to show that those countries that are seen as more corrupt are also those that have lower levels of compliance with international anti-trafficking policies, and vice versa.

This paper illustrates the links between those crimes from a different perspective, by means of reported experiences of trafficking-related corruption in Europe, particularly in South-Eastern countries. It is important to clarify from the beginning that this study is not suggesting by any means that corruption is prevalent or that it exclusively affects this region. Most public officials carry out their tasks following the rule of law. However, even if they are a minority, trafficking-related corruption cases have been reported in many countries within and outside Europe. The analysis and classification of data on these cases helps to offer an overview of their diversity and complexity. After describing the general patterns of public officials' involvement in human trafficking, this paper studies the main legislative and institutional measures on this issue at the international and European level. In this section, the proposals for combatting this specific form of criminality suggested by the Programme against Corruption and Organised Crime in South-eastern Europe (PACO), created by the Council of Europe, are subject to special attention. Finally, this paper addresses the convenience of dealing with trafficking-related corruption as a threat to national and/or human security.

\section{EXPERIENCES OF TRAFFICKING-RELATED CORRUPTION IN SOUTH- EASTERN EUROPE}

\subsection{Sources and methodology}

In order to give an overview of the different patterns of trafficking-related corruption in South-Eastern Europe, a wide range of academic literature and institutional reports have been analysed so as to gather together and classify all the data available for this purpose. It is important to note that the collection of data on trafficking-related corruption is very limited all over the world. Most reporting mechanisms "routinely fail to mention the link between public corruption and human 
trafficking" (Kendall, 2011, 40), and only a few governments study the problem (Gounev \& Bezlov, 2010, 33), despite its importance. For this reason, specific reports on cases going to court and leading to conviction are very rare. However, in spite of these difficulties, it is possible to collect some data through studies on human trafficking that do mention corruption, even if it is only tangentially.

One of the analysed sources is the report released by the so-called "PACO Networking" project, launched in 2001 by the Council of Europe, as an activity under the PACO Programme against Corruption and Organised Crime in South-eastern Europe. Among the various activities organised within the PACO Networking project, a regional seminar was held from 19 to 22 June 2002 in Portoroz, Slovenia, in which the specific problem of corruption in connection with trafficking in human beings was addressed. Representatives of anti-trafficking organisations provided information on corruption related to trafficking on each of the participating countries: Albania, Bosnia and Herzegovina, Bulgaria, Croatia, Hungary, Moldova, Romania, Slovenia, and Macedonia, The Federal Republic of Yugoslavia (Serbia and Montenegro since 2003).

Another source that expressly addresses trafficking-related corruption is the United States Department of State Annual Report on Human Trafficking (TIP Report), which assesses countries' efforts to combat human trafficking by evaluating the extent to which each country's policies comply with the Trafficking Victims Protection Act (TVPA). The TIP Report places countries into one of three categories: Tier 1 States, which met minimum anti-trafficking standards; Tier 2 States which did not meet such standards, but were taking active steps to do so; and Tier 3 States which neither met such standards, nor were taking active steps to do so. Precisely, official complicity in human trafficking is one of the factors considered to determine if a country is placed in Tier 3.

Cases of trafficking-related corruption in the area of study were also disclosed in other sources such as country reports by the special rapporteur on trafficking in persons, academic literature on corruption and organised crime, and reports by various institutions like the United Nations Office on Drug and Crime, DCAF Brussels and Transparency International, among others. 


\subsection{Results}

The analysis of the data contributes to the confirmation of the hypothesis held by previous studies: corruption and human trafficking are closely related. It is necessary to avoid generalisations and assume that all (or even the majority) of public officials are corrupt, but it is also important to identify areas presenting opportunities for corruption. The reported experiences show that corruption can be present in every stage of the trafficking chain: recruitment, transportation and exploitation. Corruption was also reported to be used in trafficking for different types of exploitation: sexual, labour exploitation or "newer" modalities, such as exploitation in begging or in criminal activities. Moreover, the collected data illustrate how opportunities for corruption may arise not only during the commission of the crime, in the trafficking chain, but also in the criminal justice chain, and in the protection and support to victims.

In order to provide a more precise picture of the different modalities of trafficking-related corruption. The collected data has been classified into the following categories:

1. Corruption of migration and border authorities

2. Police corruption

3. Administrative corruption

4. Corruption at embassies

5. Judicial corruption

6. Political corruption

\subsubsection{Corruption of migration, border and consular authorities.}

Perhaps the most obvious example of trafficking-related corruption is that of border guards who are solicited to turn a blind eye to improper documentation or to avoid scrupulous checking of vehicles holding victims. In Europe, the removal of controls over internal borders as a consequence of Schengen and the strengthening of migration policies, has increased the need for corruption to allow human trafficking at the external borders of the EU. Thus, although in some countries the need to bribe migration, border and consular authorities to obtain forged identification documents or visas under false grounds has been reduced, corruption is still an important modus operandi for trafficking people from East Europe, Africa and Asia (Rusev, 2013). Transparency international (TI) has reported the existence of several cases involving 


\section{Secururity}

high-level officials at embassies found to be issuing numerous visas to organised crime networks in return for payments (TI, 2011). For instance, in 2015, a Bosnian consular official, based in Paris, was charged with sustained abuse of position for issuing travel documents to facilitate the movement of potential labor trafficking victims in exchange for money (TIP, 2016). In Kosovo, several public officials, including in the Ministries of the Interior, Social Affairs and Labour, and Commerce and Industry were investigated for visa fraud rings (TIP, 2015). Moreover, allegations of border guards' involvement in human trafficking were also reported in Moldova (Kara, 2010).

\subsubsection{Police corruption}

The majority of trafficking-related corruption cases involved police officers (PAC0, 2002; Special Rapporteur, 2005; Gounev \& Bezlov, 2010; Antonopoulos \& Tagaroy, 2012; Rusev, 2013; TIP 2015; TIP 2016). Several reports include cases of police officers turning a blind eye to places where exploitation is taking place. The PACO project informed of situations like this in Bosnia and Croatia (2002). In other occasions, authorities may obstruct investigations, for instance, by warning about imminent raids. These experiences were reported in Bosnia (Special Rapporteur, 2005; TIP, 2015), Bulgaria (TIP, 2016), Romania (TIP, 2016) and Croatia (PACO, 2002). A case was reported in Moldova in which a police officer accepted a bribe to convince their colleagues to close the investigation (TIP, 2016). The analysed data suggests that the cooperation with traffickers often occurs in exchange of money or sexual services (PAC0, 2002; TIP, 2015). It is also possible that police officers who have a second job at bars or clubs where sexual exploitation occurs might face a conflict of interests that leads to complicity in trafficking (PACO, 2002; Special Rapporteur, 2005). Sometimes corruption is much more subtle than a payment of money in exchange of services that facilitate trafficking, and it has more to do with longstanding relationships of mutual favours, which makes it more difficult to detect (Webb \& Burrows, 2009).

Cooperation with traffickers might go beyond failing to act or obstructing investigations. Cases of police officers prosecuted for actively engaging in human trafficking rings themselves have been reported in Bosnia (PACO, 2002; TIP, 2015; TIP, 2016), Bulgaria (Gounev \& Bezlov, 2010; TIP, 2015; TIP 2016), Greece (Antonopoulos \& Tagarov, 2012), Kosovo (TIP, 2015; TIP, 2016), Macedonia (TIP 2015; TIP, 2016), Moldova (TIP, 2016), Romania (TIP, 2016) and Montenegro (PAC0, 2002). For instance, in 2009 four police officers were arrested for their alleged participation in a sex-trafficking ring, 


\section{Seccurity}

believed to have brought hundreds of women to Greece from Eastern Europe and the Balkans (Antonopoulos \& Tagarov, 2012). In January 2015, a police officer was sentenced to seven years of imprisonment for trafficking in Moldova (TIP, 2016). More recently, in March 2016, prosecutors issued an arrest warrant to two police officers accused of forcing a university student to sell drugs and recruit his female classmates to prostitute themselves and sell drugs in Bulgaria (TIP, 2016), which may be a case of human trafficking for the purposes of sexual and criminal exploitation.

When studying the socio-economic background of traffickers, Atanas Rusev points out a particularly interesting situation that occurs in Bulgaria. According to this study, security officials who were fired during the restructuring of the public sector in the early nineties can use their social and professional background to enter corruption networks, employ their former colleagues and active officers, and thus engage in criminal activities like trafficking whilst securing protection from investigations (Rusev, 2013).

Cases of police corruption were reported not only during the commission and prosecution of the crime, but also regarding victims' protection. Although no information about particular cases in the area has been disclosed, anti-trafficking institutions warn that official cooperation with traffickers can perpetuate situations of exploitation and guarantee re-victimisation of any person trying to escape, since corrupt police officers would bring them back to their traffickers or deport them before testifying (PAC0, 2002; UNODC, 2011).

\subsubsection{Judicial corruption.}

Although the judiciary is much less targeted by organised crime than the police, judges and prosecutors might facilitate human trafficking by avoiding investigations, influencing trials, or giving less harsh punishments. For instance, there have been allegations of judges who imposed sentences on convicted traffickers that do not correspond with the severity of the crime, like fines alone, or that have reserved convictions on appeal on weak grounds in Moldova (TIP, 2016).

\subsubsection{Political corruption.}

Access of traffickers to politicians has been reported to be relatively common in South East Europe and former Soviet republics (Rusev, 2013). Given the large profits from trafficking laundered in the legal economy, it is not uncommon for ring leaders to 


\section{Seccurity}

become wealthy local businessmen with influence on local political elites or even to obtain political positions themselves (Rusev, 2013). For instance, a sitting member of parliament of Albania had prior convictions for trafficking-related offenses (TIP, 2015); and a former municipal councillor in Bulgaria was charged with leading an organised group involved in human trafficking (TIP, 2016). The most flagrant example is the amendment to the Bulgarian Penal Code provisions related to human trafficking in 2006 introduced by certain MPs who allegedly had relationships with two well-known convicted traffickers, who in turn received minimal punishment (Gounev \& Bezlov, 2010).

\subsubsection{Administrative corruption.}

This category comprises other reported cases of public officials' involvement in human trafficking, different from those reported above. It includes labour inspectors who are approached to obtain work permits in order to legalise the status of the victims so as to facilitate and perpetuate exploitation (Rusev, 2013), as reported in Kosovo (TIP, 2016) and Macedonia (TIP, 2016). It also refers to municipal officers who are bribed to obtain licences for establishments that facilitate trafficking and exploitation. For instance, in September 2015, Greek authorities arrested three municipal employees who had allegedly accepted bribes in exchange for issuing permits to clubs and bars where trafficking victims were sexually exploited (TIP, 2016). Finally, this category embraces allegations of corruption in governmental institutions specifically created to fight crime and protect trafficking victims, such as the former head of the interior ministry's division to combat organised crime and officers of the Centre for Combating Trafficking in Persons in Moldova (TIP, 2016); the head of a Moldavian human rights agency for forcing children to beg in Russia (TIP, 2015), and workers of state-run orphanages in Ukraine accused of enabling the sex and labour trafficking of children housed there (TIP, 2016).

\section{INTERNATIONAL AND EUROPEAN RESPONSES TO TRAFFICKING- RELATED CORRUPTION}

Despite the existence of important links between both crimes, a brief analysis of the most relevant European and international legislation shows that corruption has been 


\section{Seccurity}

generally mostly overlooked or completely ignored in most anti-trafficking policies. The first international treaties for the abolition of the so-called white slavery did not mention public officials' involvement at all. They were mainly focused on protecting the interest of the States in controlling migration and the abolition of prostitution.

It is not until 2000 that we can find the first connection between human trafficking and corruption in international legislation. This connection indirectly appears when both crimes are associated with organised crime. Thus, Article 8 of the United Nations Convention against Transnational Organized Crime criminalises corruption in relation to organised crime and these provisions may apply to human trafficking cases, since according to Article 1 they apply mutatis mutandis to the Protocols hereto (the Palermo Protocol being one of them). However, there is no explicit reference to the participation of public officials in trafficking.

The need for an international commitment to recognise the crucial role of corruption in anti-trafficking strategy was consolidated in the 2010 UN Global Plan of Action to Combat Trafficking in Persons (A/RES/64/293, 2010). In this resolution, States Members of the UN manifested their political will to "investigate, prosecute and punish corrupt public officials who engage in or facilitate trafficking in persons and promote a zero-tolerance policy", and to "strengthen or continue to strengthen coordination and cooperation among States in combatting crimes that might be connected with trafficking in persons, including money-laundering, corruption, smuggling of migrants and all forms of organized crime".

At the European level, the most recent anti-trafficking instruments have also begun to explicitly recognise the important role of corruption in human trafficking. The Council of Europe Convention on Action against Trafficking in Human Beings of 2005 (Art. 24.c) and Directive 2011/36/EU on preventing and combatting trafficking in human beings and protecting its victims. (Art.4.3) envisage the commission by an agent or public official in the performance of their duties as an aggravating circumstance. This provisions have been implemented by most national legislations.

Precisely, as stated above, the PACO Networking Project, launched by the Council of Europe, constituted a forum of great importance to address the specific problem of corruption in connection with human trafficking in South-Eastern Europe. Within this project, not only the risks were identified, but also several measures to prevent and prosecute these practices were suggested. Officials responsible for mutual legal assistance from ten countries established networks among themselves to offer 
specific training for judges, prosecutors and other law enforcement authorities and, above all, to increase the exchange of experience and cooperation between judicial and investigative authorities from different countries.

In particular, in order to prevent trafficking-related corruption, they suggested increasing awareness by means of media reports and campaigns that publicise cases, as well as encouraging research on the issue, with the final objective of mobilising public opinion. The elaboration of codes of conduct and guidelines for public officials, which include initiatives to reduce conflict of interest by regulating the possibility of having a second job, were also recommended. Moreover, the PACO project recognised the need to increase financial support and provide training to provide officials with specific skills to avoid and identify trafficking-related corruption.

Regarding prosecution, enhancing cooperation, both nationally and internationally and between anti-trafficking and anti-corruption units was considered crucial for achieving fruitful investigations. The adoption of multidisciplinary units that also collaborate with non-governmental organisations was highlighted. These multidisciplinary units are supposed to collect and share information on trafficking experiences and the roles played by corrupt officials. Moreover, the PACO project underlined the need to ensure that financial investigations are carried out in parallel to criminal investigations to identify and confiscate the proceeds of crimes.

Several years after this project, the risk still persists. Most countries in the region do not report any investigation, prosecutions or convictions of government officials in human trafficking, despite allegations of existing cases (TIP, 2016). However, it is fair to say that some governments are demonstrating efforts to combat this problem. For instance, the TIP Report highlights the case of Belarus, where the government drafted a 2016-2018 State Program on Countering Crime and Corruption that includes anti-trafficking activities (TIP, 2016).

\section{FINAL THOUGHTS: APPROACHING TRAFFICKING-RELATED CORRUPTION AS A SECURITY CHALLENGE?}

After the analysis of some reported trafficking-related corruption experiences, it is possible to conclude that both crimes are strongly related, to the extent that it is even possible to affirm that corruption is one of the multiple elements that make human trafficking possible. Trafficking-related corruption constitutes a threat to several 
values that have traditionally been associated with national security, such as the defence of national interests and the constitutional system, because it undermines the public's trust in those who are supposed to protect it. In transnational cases, particularly when consular staff is involved, trafficking-related corruption can also be damaging for foreign relations. Nevertheless, trafficking-related corruption constitutes above all a human security risk, since it affects peoples' freedom to live with dignity, meeting their basic needs and without fear (Tăbușcă, 2015).

Despite the importance of this problem, corruption has been a historically forgotten element in anti-trafficking policies. Only very recently, the links between both crimes are slowly beginning to be recognised, although mainly in terms of prosecution. Traditionally, the legal response to these crimes followed a national security approach. National security solutions to human trafficking prioritised the interests of the State in reducing migration and crime (Lobasz, 2009). This is mainly the perspective followed by the Palermo Protocol. Even if it also includes measures to protect victims' human rights, securitarian issues surrounding trafficking are the true driving force (Gallager, 2002). This approach has had benefits, and has even been embraced by activists, because it increases the attention and resources devoted to that issue (Lobasz, 2009), and allows for the conviction of traffickers and complicit corrupt officials. However, focussing simply on protecting the national interest in controlling borders also has unsatisfactory consequences. National security approaches involve the tightening of migration controls, which, as explained above, increases the need for corruption; and the deportation of victims, which intensifies opportunities for re-trafficking.

For this reason, to reduce trafficking-related corruption it is necessary to move beyond a state-centred to a people-centred notion of security (Kreindenweis \& Hudson, 2015). Reframing human trafficking (and related corruption) as an issue of human security shall provide the means to "holistically describe what trafficking is", taking into account elements that were overlooked before, which will improve the identification of factors of victimisation and the establishment of effective anti-trafficking policies (Kreindenveis \& Hudson, 2015). Ultimately, if trafficked people were not considered a threat to the State, but victims of human rights violations, counter-trafficking policies would focus more on social policies, which would contribute to the emancipation and empowerment of victims. 


\section{REFERENCES}

1. Antonopoulos, G., \& Tagarov, N. (2012). Greece: the Politics of Crime. In P. Counev \& V. Ruggiero (Eds.), Corruption and Organized Crime in Europe (pp. 125-144). Oxon: Routledge.

2. Bales, K. (2005). Understanding Global Slavery. Berkeley: University of California Press.

3. Cho, S., Dreher, A., \& Neumayer, E. (2014). Determinants of Anti-Trafficking Policies: Evidence from a New Index. The Scandinavian Journal of Economics, 116 (2), 429-31.

4. Gallagher, A. (2002). Trafficking, Smuggling and Human Rights: Tricks and Treaties. Forced Migration Review, 12 (January), 25-28.

5. Gounev, P. \& Bezlov, T. (2010). Examining the links between organised crime and corruption. Sofía: CSD.

6. Kara, S. (2010). Sex Trafficking: Inside the Business of Modern Slavery. New York: Columbia University Press.

7. Kendall, V. (2011). Greasing the Palm: An Argument for an Increased Focus on Public Corruption in the Fight Against International Human Trafficking. Cornell International Law Journal, Vol.40, 33-47.

8. Kreidenweis, A. \& Hudson, N.F. (2015). More than a Crime: Human Trafficking as Human (In)Security. International Studies Perspectives, 16 (1), 67-85.

9. Lobasz, J.K. (2009). Beyond Border Security: Feminist Approaches to Human Trafficking. Security Studies, Vol. 18, 319-344.

10. Lyday, C. (2001, October). The Shadow Market in Human Beings: An AntiCorruption Perspective. Paper presented at the $10^{\text {th }}$ IACC, Prague. http://www.10iacc.org/download/workshops/cs32b.pdf

11. PACO Project (Council of Europe). (2002). Trafficking in Human Beings and Corruption. Report on the regional seminar Portoroz, Slovenia, June 2002. Retrieved from:

http://lastradainternational.org//sidocs/297\%20Trafficking\%20and\%20Corrupt ion\%20(PACO).pdf

12. Report on the Special Rapporteur on trafficking in persons, especially women and children, Sigma Huda. (2005, November). Addendum MISSION TO BOSNIA AND HERZEGOVINA E/CN.4/2006/62/Add.2 30. 
13. Rusev, A. (2013). Human Trafficking: Border Security and Related Corruption in the EU. Brussels: DCAF.

14. Tăbușcă, S.M. (2015). Trafficking in Persons, a Threat to Human Security in the Developed Countries. The Case of the European Union in the Era of Globalization. Nationa/ Strategies Observer, 2 (1), 255-265.

15. TI. (2011). Corruption and Human Trafficking. TI Working Paper 3/2011.

16. UNODC. (2013). The Role of Corruption in Trafficking in Human Beings. UNODC Issue Paper.

17. US Department of State. (2015). Trafficking in Persons Report 2015 (TIP 2015). Washington DC, July 2015.

18. US Department of State. (2016). Trafficking in Persons Report 2016 (TIP 2016). Washington DC, June 2016.

19. Van Dijk, J. \& Van Mierlo, F. (2011). Indicators of Corruption: Further Explorations of the Link Between Corruption and Implementation Failure in Anti-Trafficking Policies. Tilburg: International Victimology Institute Working paper.

20. Webb, S. \& Burrows, J. (2009). Organised Immigration Crime: A Post-Conviction Study. Research Report 15. London: Home Office.

21. Zhang, S. \& Pineda, S. (2008). Corruption as a Causal Factor in Human Trafficking. In D. Siegel \& H. Hans (Eds.), Organized Crime: Culture, Markets and Policies (pp. 41-55). New York: Springer. 